Revista Aspas

ppgac - USP

\title{
Especial
}

\section{ACOMPANHAMENTO DE PROCESSOS DE CRIAÇÃO: ALGUMAS REFLEXÕES}

\author{
MONITORING OF CREATION PROCESSES: \\ SOME REFLECTIONS
}

SEGUIMIENTO A LOS PROCESOS DE CREACIÓN: ALGUNOS PENSAMIENTOS

\section{Cecilia Almeida Salles}

Cecilia Almeida Salles

Professora titular do Programa de Pós-Graduação em Comunicação e Semiótica da Pontifícia Universidade Católica de São Paulo. Coordenadora do Grupo de Pesquisa em

Processos de Criação. Autora dos livros Gesto Inacabado (1998), Crítica Genética (2008), Redes da Criação (2006), Arquivos de Criação: arte e curadoria (2010) e Processos de criação em grupo: diálogos (2017). 


\section{Resumo}

O objetivo deste artigo é propor algumas reflexões sobre a metodologia de pesquisa no acompanhamento de processos cênicos, no âmbito dos estudos sobre processo de criação. É apresentado um histórico do desenvolvimento de tais pesquisas, no Programa de Pós-Graduação em Comunicação e Semiótica da Pontifícia Universidade Católica de São Paulo, que passaram a oferecer uma abordagem crítica de processo para a produção artística. De modo mais específico, são apresentados alguns possíveis propósitos, contextos de acompanhamentos e formas de registros das observações, a partir de alguns exemplos. E por fim são propostos alguns caminhos, diante dos questionamentos relativos à fundamentação teórica.

Palavras-chave: Processo de criação, Crítica de processo, Acompanhamento.

\section{Abstract}

This article proposes some reflections on the research methodology in the monitoring of theatrical processes within the scope of creation process. It is presented a history of the development of such researches in the Graduate Program in Communication and Semiotics from the Pontifical Catholic University of São Paulo, which began to offer a critical approach to the artistic production process. Specifically, some possible purposes are presented, as well as contexts of monitoring and forms of recording observations, from a few examples. Finally, some paths are proposed on the questions concerning the theoretical foundation.

Keywords: Process of creation, Review of process, Monitoring.

\section{Resumen}

El objetivo de este artículo es proponer algunas reflexiones sobre la metodología de investigación en el seguimiento de procesos escénicos, en el ámbito de los estudios sobre proceso de creación. Se presenta un historial del desarrollo de las investigaciones en el Programa de Postgrado en Comunicación y Semiótica de la Pontificia Universidad Católica de São Paulo, que pasaron a ofrecer un abordaje crítico de proceso para la producción artística. Específicamente, se presentan posibles propósitos, contextos de seguimientos y formas de registros de las observaciones, a partir de algunos ejemplos. Y por fin se proponen algunos caminos, ante los cuestionamientos relativos a la fundamentación teórica.

Palabras clave: Proceso de creación, Crítica de proceso, Seguimiento. 
O objetivo desse artigo é propor algumas reflexões sobre a metodologia de pesquisa no acompanhamento de processos cênicos, no âmbito dos estudos sobre o processo de criação. Ao longo do desenvolvimento dessa crítica de processos, em diálogo com diferentes teorias e grande diversidade de registros ou documentos de percursos criativos em manifestações distintas, venho propondo alguns instrumentos teóricos para adensar a compreensão da criação. Trata-se de uma possível teoria crítica de processo que discute a criação como rede em construção em diálogo com o pensamento da complexidade ${ }^{1}$. Essas reflexões teóricas são tema dos meus livros Gesto Inacabado: Processo de criação artística, Redes da criação: construção da obra de arte e, mais recentemente, Processos de criação em grupo: diálogos.

O desenvolvimento desses estudos se dá no contexto de uma constante ampliação de seus limites, na medida que sempre deram especial atenção à experimentação contemporânea, a qual exige, em muitos casos, a expansão do olhar do crítico interessado em processos de criação. Além disso, a metodologia vem se expondo a outros caminhos para além dos estudos dos arquivos pessoais dos artistas - sem abandoná-los -, como exemplo, o acompanhamento dos processos em grupo, mais especificamente os cênicos.

Para iniciar essas reflexões, proponho pensarmos no propósito e no contexto de tais acompanhamentos. De um modo bastante amplo, qual o objetivo de assistir a ensaios, debates, workshops, palestras etc. e qual a relação do observador com o grupo? Quanto aos propósitos, seria importante levantar algumas possibilidades que levassem a questões gerais metodológicas desse acompanhamento, bem como a algumas de suas especificidades.

Não há dúvida de que, no caso dos processos em grupo, a presença de alguém ao longo do percurso é sempre facilitada e menos artificial do que no caso dos processos ditos individuais ${ }^{2}$. O grupo se amplia, mas é sempre

1. Essa teoria crítica da criação foi construída em diálogo com a semiótica de Charles S. Peirce (1931-1935), o conceito de rede de Pierre Musso (2004) e pensadores da complexidade e da cultura, como Edgar Morin (1998) e lúri Lotman (1998).

2. Colapietro (2014), ao discutir o sujeito sob o ponto de vista da semiótica, diz que o artista, em nosso caso, não é uma esfera privada, mas um agente comunicativo. É distinguível, porém não separável de outros, pois sua identidade é constituída pelas relações com os outros não é só um possível membro de uma comunidade, mas a pessoa, como sujeito, tem a própria forma de uma comunidade e ressalta o que parece de extrema relevância para se colocar em crise a oposição entre processos em grupo e processos individuais. (Cf. SALLES, 2017). 
mais um olhar. Não se pode falar de observador neutro. Há sempre interação entre os membros do grupo e o observador. Acredito que, no contexto do pensamento da complexidade e fugindo da crença na objetividade das ciências clássicas, partimos da "inevitável" interação de subjetividades. Se tomarmos o conceito de criação como rede ${ }^{3}$, o observador será sempre parte da rede da criação que o grupo está desenvolvendo.

Dando continuidade à discussão sobre acompanhamento sob o ponto de vista do grau de envolvimento do observador, já se colocam algumas perguntas que vão gerar, por sua vez, modos diferentes de acompanhamento. Trata-se de um pesquisador acadêmico, um crítico de processo, um crítico das artes cênicas, um pesquisador das artes cênicas, um artista, um artista/ pesquisador, de fora do grupo, que está fazendo um mestrado ou doutorado, ou de um pesquisador integrante do grupo, que vivencia o próprio processo? Trata-se de um pesquisador externo ao grupo, ou alguém convidado para acompanhar o processo? Essas são algumas possibilidades, sabendo que não se pode esgotar tal listagem. O importante a destacar é que esses propósitos diferentes geram modos de acompanhamento diversos, assim como "produtos", só para citar uns exemplos: textos críticos, pesquisas acadêmicas, documentários etc. Os registros audiovisuais de cineastas convidados para acompanhar o grupo, que podem gerar documentários, serão discutidos mais adiante, nos relatos sobre os processos de Evaldo Mocarzel.

Outras questões relativas à metodologia do acompanhamento são o tempo e os modos de registrar as observações. O tempo está relacionado a muitas variáveis, tais como as possibilidades e propósitos do pesquisador, a abertura do grupo etc. Quanto ao registro, minha experiência leva-me a ressaltar a preocupação de não ser invasivo e de entender que tipo de interação o grupo espera, e a busca de linguagem comum e cuidados com a postura crítica. Essas observações podem gerar, por exemplo, anotações verbais ou audiovisuais.

3. O conceito de criação será apresentado, de modo resumido, mais adiante. Cf. Cecilia A. Salles (2006; 2017). 


\section{Diferentes contextos de acompanhamento}

Minha primeira experiência nesse campo foi o acompanhamento do processo de construção da instalação da artista visual norueguesa Inghild Karlsen, desenvolvido na Oficina Cultural Oswald de Andrade para a XXII Bienal Internacional de São Paulo em 1994, e enfrentando os problemas de uma primeira pesquisa com esse objetivo.

A primeira dificuldade que se colocava era a presença de alguém externo ao processo. No entanto, nesse caso, a artista foi agregando outras pessoas à equipe inicial, composta por ela e seu assistente. É interessante notar que a presença de assistentes é prática comum nas produções e montagens das artes visuais quando há uma espécie de divisão de trabalho. Pelo próprio fato de a artista estar na Bienal de São Paulo, por escolha de um curador de seu país, já se adiciona outra pessoa como parte integrante deste processo. Tais condições de produção são relevantes para compreendermos a facilidade de aceitação da presença de um crítico interessado em processos de criação em alguns momentos desse percurso.

O que quero destacar é que, embora a obra seja de Inghild Karlsen, em seu local de trabalho ela convivia com outras pessoas, daí minha presença ser natural e, por isso, não constrangedora ou inconveniente. A observação ocorreu, portanto, nos momentos em que o processo individual de Inghild tornava-se, necessariamente, coletivo. $O$ trabalho solitário de um artista, em seu ateliê, não ofereceria as mesmas condições e impossibilitaria essa forma de registro do percurso. Claro que há outros documentos, mas essa metodologia do acompanhamento tornaria o processo artificial.

Nesse mesmo contexto de processos de artistas da visualidade, o livro de James Lord, Um retrato de Giacometti, apresenta fotos do retrato pintado por Giacometti, acompanhadas de comentários sobre sua experiência como modelo do pintor; ou seja, o responsável pela publicação do livro fez parte do processo. Não há dúvida sobre a relevância dessa obra, já que temos acesso à relação pintor/modelo, ao clima do ateliê e à rotina de trabalho - informações difíceis de se obter sem a artificialização do processo, no caso, com o acompanhamento da produção de uma pintura por algum observador externo ao processo. James Lord menciona, ao longo do livro, os cuidados em fazer 
anotações depois do término das sessões, para que Giacometti não se sentisse invadido.

Outro exemplo que trago de minha prática crítica foi gerado por um convite para participar do projeto Um diálogo possível, de Ana Teixeira, na Companhia 2 do Balé da Cidade de São Paulo, em 2005, na condição de um dos teóricos convidados para o acompanhamento desse percurso. Desde que me foi apresentado o projeto, percebi que se esperava de mim mais do que observação.

A proposta, feita pela diretora do Balé da Cidade, Mônica Mion, e pelas diretoras cênicas responsáveis pelo projeto, Ana Teixeira e Sigrid Nora, envolvia o acompanhamento das atividades da Cia. 2 em todos os momentos em que fosse possível. Estava claro, já no tema do projeto, que eu fazia parte do grupo como uma das pessoas que, possivelmente, propiciaria novas interações, as quais se concretizariam como um dos possíveis diálogos; no entanto, não havia nada predeterminado de como isso aconteceria. No primeiro momento, foi uma experiência de três meses, em meu caso específico. No texto "Diálogos foram possíveis", um dos capítulos de meu livro Arquivos da criação: crítica e curadoria, discuto algumas questões metodológicas.

Logo de início ficou claro que ali estava sendo colocado um desafio bastante instigante, afinal, era muita coisa nova: a pouca experiência com essa metodologia e o fato de ser minha primeira experiência com dança. Por exemplo, como me comportar na observação: fazer anotações seria inibidor? Rapidamente isso foi resolvido, ao perceber que os outros participantes também tomavam suas notas. Precisava, ainda, conhecer os termos específicos da área para o estabelecimento de diálogo, trazendo, ao mesmo tempo, analogias com outras manifestações artísticas. Temia ser muito teórica, pois isso sempre cria obstáculos nas interações buscadas. Os diálogos entre universidade e comunidade artística são marcados, muitas vezes, por resultados desastrosos, quando não se encontra uma linguagem em comum. Tal preocupação e incerteza se mantiveram até o término do projeto.

Outro obstáculo enfrentado nesse acompanhamento foi a necessidade de fazer, muitas vezes, julgamentos estéticos acerca de algum momento do processo, como a qualidade de uma cena proposta. Como crítica, sempre me 
coloco na posição de tentar compreender as buscas estéticas do artista (ou artistas) estudado(s) sem emitir meus próprios juízos. Não interessa se o crítico optaria por outras escolhas nos momentos em que os artistas enfrentam a diversidade de caminhos a serem tomados, mas sim entender as tendências dessas decisões no âmbito da obra em criação.

Essas primeiras dificuldades, se não totalmente vencidas, foram, de algum modo, minimizadas. Em um momento não definido, de observadora externa do percurso de criação do grupo, passei a me sentir parte do processo.

O diálogo foi se ampliando ao longo do tempo - participando de algumas conversas no fim dos dias de trabalho e propondo referências, como a imagem de rede, filmes e a produção de um texto crítico, como resultado de minha vivência com o grupo. Alguns desses resultados serão apresentados mais adiante, mas é importante já destacar aqui que são observações de um crítico que passou a fazer parte da rede em criação, como era o propósito do projeto. São algumas conclusões que, a partir de publicações, estabeleceram novos diálogos tanto com a comunidade artística como com a acadêmica. Além disso, foram apresentadas em uma revista da área de dança contemporânea e, por oferecerem uma nova possibilidade metodológica para a crítica genética, incluídas na terceira edição de meu livro introdutório a essa abordagem crítica (SALLES, 2008).

Outro exemplo importante a ser mencionado é o projeto Crítica Genética, da Cia. Danças, dirigido por Claudia de Souza. O grupo havia entrado em contato com essa possível abordagem para a arte a partir da pesquisa de mestrado do meu orientando Marcos Villas Boas (2004), Aspectos comunicacionais dos processos coletivos, um estudo de caso sobre um processo da Cia. Danças.

Apenas poucos anos depois fiquei sabendo desse projeto artístico proposto pelo grupo e fui conversar com eles algumas vezes ao longo do percurso. O interessante a destacar nesse caso é que a interlocução com o grupo continua até hoje, com participação em outros projetos da Companhia. Acredito que tal continuidade dá algumas pistas sobre o modo como acontecem essas interações entre o crítico de processo e os grupos por ele estudados. 


\section{O que observar?}

Em muitos casos, a pergunta que move essa metodologia crítica é "o que esse acompanhamento oferece sobre o processo de criação do grupo?". O pesquisador fica, assim, exposto ao que aquele processo vai oferecendo, sem predeterminação do que vai encontrar, aberto ao acaso da pesquisa, com as marcas inevitáveis do seu olhar e de seus interesses. Meu orientando Rodrigo Arrigoni (2006), por exemplo, que defendeu o mestrado $O$ espaço comunicativo no teatro do Satyros: o ator e o espectador, era um jovem dramaturgo com intensa inquietação relativa ao que ele via como "desinteresse" da dramaturgia naquele momento com o espectador. $O$ título de sua pesquisa já mostra como seu olhar foi movido por suas preocupações.

\section{Formas de interação com o grupo}

Ao discutir alguns contextos de acompanhamento, trouxe, de modo implícito, formas de interação entre o observador e o grupo. Aqui vão alguns outros exemplos bastante significativos para essa discussão.

Dessa forma, recorro aos documentários de Evaldo Mocarzel, cujas cartas para o montador e os diferentes cortes dos filmes foram por mim estudados, e que surgiram do seu propósito de registrar os percursos de criação teatral de diversos grupos paulistas atuantes nas últimas décadas. A partir do acompanhamento audiovisual de workshops, ensaios, discussões, conversas e viagens dos grupos e espetáculos, o documentarista é responsável pela preservação da memória da história recente do teatro experimental paulista e, ao mesmo tempo, pela produção de documentários, que geram conhecimento sobre o processo de criação teatral.

Em seu acompanhamento do projeto Cia. Livre 10 anos, essas interações ganharam contornos interessantes, na medida que cinema e teatro colaboraram mutuamente, colocando o cineasta como parte da rede colaborativa de criação dos grupos teatrais documentados.

Nesse caso, a experimentação proposta pela diretora Cibele Forjaz e acolhida por ele, representa bem essa interação. $O$ documentarista explica para a montadora Guta Pacheco: 
Minha intenção inicial era fazer um documentário rigorosamente observacional com a Companhia Livre, sem entrevistas, não calcado em palavras, que costumam ser traiçoeiras, sobretudo no resgate da memória de um grupo de teatro. Queria que a documentação, os lampejos de memória irrompessem da observação da ação de reencenar todos os espetáculos da companhia, mas, logo no primeiro dia de filmagem, constatei que isso não seria possível, pois, após ter criado uma espécie de 'quarta parede' documental, para observar a ação dos trabalhos, Cibele Forjaz rompeu o recato da observação, interagiu com a câmera e acabou criando um plano metalinguístico, dirigido por ela, no qual o fotógrafo e eu fomos colocados no centro da imagem, um plano com a câmera bem alta, no teto do teatro.

Ele acolhe a proposta. E continua seu diálogo com a futura montadora do documentário:

Como sabemos, a linguagem do documentário é uma espécie de arquitetura do inesperado, precisa ter o acaso como elemento de composição nos nossos sons e nas nossas imagens, uma porosidade ao imprevisto e, logicamente, pelo menos para mim, uma preocupação constante com a alteridade, com o 'outro', que também pode ajudar a sugerir os procedimentos de linguagem a serem adotados na construção da própria imagem dentro do filme. Diante dessa lúdica intervenção inicial de Cibele Forjaz, cheguei à conclusão de que uma observação rigorosa demais não era o melhor caminho para esse projeto sobre a Cia. Livre e, além do mais, o Teatro é o templo das atrizes, dos atores e da palavra.

Como se vê, a intervenção da diretora gerou uma nova maneira para Mocarzel fazer seu documentário. O cineasta revê, ao longo do processo, sua escolha inicial pela ausência de entrevistas, encontrando novos recursos através das próprias entrevistas:

Percebi mais uma vez que seria cruel e, até mesmo equivocado, fazer um documentário sobre um grupo de teatro sem entrevistas, rejeitando de algum modo a palavra. Resgatei então a opção pela entrevista e, pouco a pouco, confesso que também acabei interagindo com todos, não apenas como cineasta, realizador de um filme documentário, mas também como dramaturgo em processo.

E, por fim, explicita critérios relativos ao uso de entrevistas a partir do que não quer: "mas não queria que esse nosso filme fosse um talking heads do 
início ao fim, um daqueles documentários com cabeças falantes, que quase sempre enveredam por aquela tediosa atmosfera de reportagens televisivas".

Há, ainda, casos nos quais o pesquisador observador é “absorvido" pelo processo do grupo.Trago o exemplo deAlexandre MauroToledo, meu orientando, que defendeu seu doutorado Novas configurações da direção teatral, em 2011. Ele acompanhou o processo de um grupo mineiro que enfrentou conflitos com o diretor, já próximo da estreia. Alexandre, então, assumiu a direção, porque já era parte da rede daquele processo e conhecia os princípios que direcionavam o grupo naquele processo específico.

Algo semelhante aconteceu com Evaldo Mocarzel, no projeto Kastelo, uma adaptação de $O$ Castelo, de Franz Kafka, realizada pelo Teatro da Vertigem, que também enfrentou alguns embates, como vemos, tão comuns em tais processos. Nesse caso, o cineasta, que vinha acompanhando o processo como parte de seu projeto anteriomente mencionado, passa a assinar a dramaturgia juntamente com Sérgio Pires.

\section{Algumas reflexões críticas}

A metodologia colocada aqui em debate enfrenta também alguns questionamentos relativos à fundamentação teórica. Faz-se aqui a pergunta: como a crítica de processos de criação pode auxiliar na leitura das observações dos acompanhamentos, produzindo conhecimento sobre criação?

O primeiro aspecto a ser destacado é que se trata de uma abordagem crítica com as mesmas inquietações de quem se propõe a acompanhar o processo. Essas buscas em comum podem trazer à tona a importância das anotações e dos diários de atores e diretores (só para citar alguns exemplos) dos percursos acompanhados, cuja leitura pode ampliar o conhecimento sobre a criação daquele grupo. Ao mesmo tempo, os instrumentos de natureza geral dos processos, oferecidos por essa abordagem crítica, talvez possam gerar reflexões sobre as especificidades dos processos acompanhados.

Para exemplificar essa questão, volto ao processo do Balé da Cidade, por mim acompanhado, trazendo, inicialmente, algumas das questões gerais dos processos, no âmbito do conceito de criação como rede. O processo de criação pode ser descrito como percurso sensível e intelectual, de construção 
de objetos artísticos, científicos e midiáticos que, na perspectiva semiótica (PEIRCE, 1931-1935), como movimento falível com tendências e sustentado pela lógica da incerteza, engloba a intervenção do acaso e abre espaço para a introdução de ideias novas. Um processo contínuo, sem ponto inicial nem final; um percurso de construção inserido no espaço e no tempo da criação, que inevitavelmente afeta o artista.

As tendências são rumos vagos que orientam o processo de construção das obras no ambiente de incerteza e imprecisão; elas geram trabalho, em busca de algo que está por ser descoberto. $O$ desenvolvimento do processo leva a determinadas tomadas de decisão que propiciam a formação de linhas de força. Estas, por sua vez, vão dando consistência aos objetos em construção. Ao longo do percurso, são estipuladas restrições ou delimitações de naturezas diversas que possibilitam a construção da obra. As tendências dos processos podem ser observadas sob o ponto de vista da construção do projeto poético e das práticas comunicativas.

Para a discussão sobre o Balé da Cidade, dou destaque ao projeto poético ou aos princípios direcionadores do processo. Nesse espaço de tendências vagas está o projeto poético do artista, formado por princípios direcionadores, de natureza ética e estética, presentes nas práticas criadoras, relacionados à produção de uma obra específica, e que atam a obra daquele criador como um todo. São princípios relativos às singularidades dos artistas ou grupos; são planos de valores, formas de representar o mundo, gostos e crenças que regem seus modos de ação.

O acompanhamento do processo deixou explícito que o percurso era conduzido por propostas que se sustentavam em uma sólida vertente ética. Sob esse ponto de vista, havia uma contínua discussão sobre o comprometimento que envolvia todos, pelo fato de o projeto estar sendo desenvolvido em um órgão público. Isso estava implícito em uma das questões propostas pelas diretoras para todos os participantes: "no seu entendimento, que outras ações semelhantes a esta é possível esperar de uma companhia oficial de dança, que entende seu papel político no cenário nacional da dança?".

Esse comprometimento estava na base da proposta estética do projeto, que poderia ser definida como a necessidade de questionamento de modelos 
de atuação e a consequente busca de modos de romper com uma matriz codificada ou com um corpo com memória cristalizada. Desse modo, o que se propunha era o abalo de uma tradição vivenciada pelo corpo dos bailarinos. Como se apropriar de seu corpo sem a máscara e as certezas trazidas pelo conhecido? O caminho escolhido para esse questionamento de certezas foi a busca por diálogos múltiplos. Como bailarinos de uma companhia mantida por verba pública, via-se na pesquisa um meio de evitar uma possível estagnação de procedimentos no âmbito da dança propriamente dita.

De modo mais preciso, isto é, no que se colocava como desafio para aqueles corpos específicos, matéria-prima dos bailarinos, eram questionamentos sobre a resistência oferecida e a consequente manutenção em território conhecido. Em outras palavras, o que estava em jogo era a disponibilidade (ou não) desses corpos para o abalo de seus hábitos. As dificuldades enfrentadas pelos propositores do projeto nem sempre eram explícitas, mas lá estavam de modo latente.

Sob o ponto de vista dos aspectos gerais do processo, a inquietação estava na relação dos artistas do grupo com a matéria-prima escolhida, que sempre nasce da tensão entre suas propriedades e sua potencialidade. Esse embate se reverte em conhecimento da matéria, o que envolve uma aprendizagem de sua história, de seus limites e de suas possibilidades. No momento da concretização da obra, o artista estabelece um relacionamento íntimo e tensivo com a matéria escolhida, por meio do qual seu projeto se tornará palpável. Na manipulação e transformação da matéria há mútua incitação. Nessa troca recíproca de influência, artista e matéria vão se conhecendo, reinventam-se e, consequentemente, ampliam seus significados.

Termino tais reflexões sobre a metodologia dos acompanhamentos dos processos adicionando essa proposta de leitura crítica. As questões gerais dos processos de criação nos auxiliam, a meu ver, a chegar às especificidades com maior acuidade ou precisão, deixando assim uma proposta teórica para o modo como as informações obtidas nos acompanhamentos dos processos podem gerar conhecimento sobre as especificidades da criação daquele grupo. 


\section{Referências bibliográficas}

ARRIGONI, R. O. B. O espaço comunicativo no teatro do Satyros: o ator e o espectador. 2006. Dissertação (Mestrado em Comunicação e Semiótica) - Pontifícia Universidade Católica, São Paulo, 2006.

COLAPIETRO, V. M. Peirce e a abordagem do self: uma perspectiva semiótica sobre a subjetividade humana. São Paulo: Intermeios, 2014.

LORD, J. Um retrato de Giacometti. Tradução Célia Euvaldo. São Paulo: Iluminuras, 1998.

LOTMAN, I. La semiosfera II: semiótica de la cultura, del texto, de la conducta y del espacio. Selección y traducción Desiderio Navarro. Madrid: Cátedra, 1998.

MORIN, E. O método 4: as ideias - habitat, vida, costumes, organização. Porto Alegre: Sulinas, 1998.

MUSSO, P. A filosofia da rede. In: PARENTE, A. (org.) Tramas da rede: novas dimensões filosóficas, estéticas e políticas da comunicação. Porto Alegre: Sulina, 2004. p. 17-38.

PEIRCE, C. S. Collected papers of Charles Sanders Peirce. Cambridge, MA: Harvard University Press, 1931-1935. 8 v.

SALLES, C. A. Redes da criação: construção da obra de arte. Vinhedo: Horizonte, 2006.

Crítica genética: fundamentos dos estudos genéticos sobre o processo de criação artística. 3. ed. São Paulo: Educ, 2008.

Gesto inacabado: processo de criação artística. 5. ed. São Paulo: Intermeios, 2011.

Processos de criação em grupo: diálogos. São Paulo: Estação das Letras e Cores, 2017.

TOLEDO, A. M. Novas configurações da direção teatral. 2011. Tese (Doutorado em Comunicação e Semiótica) - Pontifícia Universidade Católica, São Paulo, 2011.

VILLAS BOAS, M. Aspectos comunicacionais dos processos coletivos: um estudo de caso na dança. 2004. Dissertação (Mestrado em Comunicação e Semiótica) - Pontifícia Universidade Católica, São Paulo, 2004.

Recebido em 23/10/2017

Aprovado em 23/10/2017

Publicado em 03/05/2018 